\title{
Bee venom attenuates neuroinflammatory events and extends survival in amyotrophic lateral sclerosis models
}

Eun Jin Yang ${ }^{1 *}$, Jing Hua Jiang ${ }^{1}$, Sang Min Lee ${ }^{1}$, Sun Choel Yang ${ }^{2}$, Hye Suk Hwang ${ }^{1}$, Myeong Soo Lee ${ }^{1}$, Sun-Mi Choi ${ }^{1}$

\begin{abstract}
Background: Amyotrophic lateral sclerosis (ALS) is a disease affecting the central nervous system that is either sporadic or familial origin and causing the death of motor neurons. One of the genetic factors contributing to the etiology of ALS is mutant SOD1 (mtSOD1), which induces vulnerability of motor neurons through protein misfolding, mitochondrial dysfunction, oxidative damage, cytoskeletal abnormalities, defective axonal transport, glutamate excitotoxicity, inadequate growth factor signaling, and neuroinflammation. Bee venom has been used in the practice of Oriental medicine and evidence from the literature indicates that BV plays an anti-inflammatory or anti-nociceptive role against inflammatory reactions associated with arthritis and other inflammatory diseases. The purpose of the present study was to determine whether bee venom suppresses motor neuron loss and microglial cell activation in $\mathrm{hSOD} 1^{\mathrm{G} 93 \mathrm{~A}}$ mutant mice.
\end{abstract}

Methods: Bee venom (BV) was bilaterally injected (subcutaneously) into a 14-week-old (98 day old) male hSOD ${ }^{\text {G93A }}$ animal model at the Zusanli (ST36) acupoint, which is known to mediate an anti-inflammatory effect. For measurement of motor activity, rotarod test was performed and survival statistics were analyzed by KaplanMeier survival curves. The effects of BV treatment on anti-neuroinflammation of hSOD $1^{\mathrm{G} 93 \mathrm{~A}}$ mice were assessed via immunoreactions using Iba 1 as a microglia marker and TNF- $\alpha$ antibody. Activation of ERK, Akt, p38 MAP Kinase (MAPK), and caspase 3 proteins was evaluated by western blotting.

Results: BV-treated mutant hSOD1 transgenic mice showed a decrease in the expression levels of microglia marker and phospho-p38 MAPK in the spinal cord and brainstem. Interestingly, treatment of BV in symptomatic ALS animals improved motor activity and the median survival of the BV-treated group (139 \pm 3.5 days) was $18 \%$ greater than control group (117 \pm 3.1 days). Furthermore, we found that BV suppressed caspase-3 activity and blocked the defects of mitochondrial structure and cristae morphology in the lumbar spinal cord of hSOD $1^{\text {G93A }}$ mice at the symptomatic stage.

Conclusion: From these findings, our research suggests BV could be a potential therapeutic agent for antineuroinflammatory effects in an animal model of ALS.

\section{Background}

Amyotrophic lateral sclerosis (ALS) is a severe paralytic disorder of the central nervous system (CNS) that is characterized by age-related degeneration or elimination of upper and lower large motor neurons of the motor

\footnotetext{
* Correspondence: yej4823@hanmail.net

'Department of Standard Research, Korea Institute of Oriental Medicine, 483

Expo-ro, Yuseong-gu, Daejeon, 305-811, Korea

Full list of author information is available at the end of the article
}

cortex, brainstem, and spinal cord [1]. ALS symptoms are characterized by muscle weakness, atrophy, spasticity, and paralysis [2]. Riluzole therapy has been shown to only improve the survival of ALS patients by a few months and has several side-effects, including asthenia, nausea, anorexia, and diarrhea [3]. Therefore, a safer and more effective therapy for ALS patients is needed in order to reduce the pain associated with this disease. Most ALS patients have the sporadic form of the disease 
while $5-10 \%$ of ALS cases are of the familial type. Familial ALS (fALS) cases are caused by autosomal dominant mutations of the human $\mathrm{Cu}-\mathrm{Zn}$ superoxide dismutase 1 (hSOD1) gene [4]. An animal model of ALS has been characterized in mice that carry the mutated hSOD1 gene with a glycine to alanine substitution at the $93^{\text {rd }}$ codon (SOD1 ${ }^{\mathrm{G} 93 \mathrm{~A}}$ ). These animals display progressive motor neuron degeneration that is similar to that observed in cases of human ALS [5]. In vivo and in vitro studies using mutant hSOD1 transgenic mice have demonstrated multiple cellular pathogenic events in motor neurons such as glutamate excitotoxicity, mitochondrial dysfunction, protein misfolding, neurofilament accumulation, and oxidative stress $[2,6,7]$.

Neuroinflammation is a pathological feature present in ALS patients and in the mutant hSOD1 mouse model [8]. As critical mediators of inflammation, activated microglia and elevated levels of tumor necrosis factor-alpha (TNF- $\alpha$ ) are detected in the CNS of ALS patients and in hSOD1 ${ }^{\text {G93A }}$ transgenic mice [9]. Previous findings point towards the critical involvement of microglia in the development of motor neuron disease; however the nature of microglial-neuronal interactions that lead to motor neuron degeneration remains unknown. One possibility that has been extensively studied in the context of other neurodegenerative diseases, especially Alzheimer's disease (AD), is the notion that chronic and detrimental microglial neuroinflammation contributes to neuronal degeneration [10]. Another study demonstrated that p38, a 38 kDa Stress Activated Protein Kinase/Mitogen-Activated Protein Kinase (SAPK/MAPK), has a key role in the development of inflammation [11]. Inhibition of p38 has been shown to produce anti-inflammatory effects by reducing cytokines such as TNF- $\alpha$, interleukin-1 (IL-1), and nitric oxide synthetase (NOS) as well as by decreasing Cox- 2 in inflammatory cells [11]. Elevated levels of TNF- $\alpha$ and TNF- $\alpha$ medicated signaling pathways are evident in a large number of neurological disorders including multiple sclerosis (MS), AD, Parkinson's disease (PD), and ALS [12-15]. Furthermore, pro-inflammatory cytokines, such as TNF- $\alpha$ and interferon-gamma (IFN- $\gamma$ ) have been proposed to be involved in ALS-like microglial activation and inflammation-induced motor neuron death [16,17].

Bee venom (BV), which is also known as apitoxin, is extracted from honeybees and is commonly used in Oriental medicine. The anti-inflammatory action of BV has shown to reduce pain in patients with chronic rheumatoid arthritis and osteroarthritis [18]. However, the mechanism by which these anti-inflammatory properties relieve the neuroinflammation associated with neurodegenerative disease is not clear. In order to explore this therapeutic mechanism, we investigated the anti-inflammatory effects of BV on motor function and survival in SOD1 ${ }^{\text {G93A }}$ mutant mice.
The present study showed decreased levels of TNF- $\alpha$ and the deactivation of p38 MAPK downstream of the TNF- $\alpha$ signaling pathway in both the brainstem and spinal cord of hSOD $1^{\mathrm{G} 93 \mathrm{~A}}$ mice after treatment with BV in the hind limbs at the ST36 acupoint. Interestingly, BV treatment reduced the number of microglial cells and astrocytes, and dramatically increased the expression of MAP2 in motor-related regions of the brainstem and spinal cord in comparison with age-matched hSOD ${ }^{\text {G93A }}$ control mice. Additionally, we showed that BV suppressed caspase-3 activity and reduced the disruption of mitochondrial structure and cristae morphology in the lumbar spinal cord of hSOD ${ }^{\text {G93A }}$ mice. Furthermore, BV treatment improved the motor coordination and prolonged the life span of familial mutant ALS animals at a symptomatic stage. Based on these findings, we suggest that BV has a neuroprotective effect against motor neuron cell death and suppresses neuroinflammation-induced disease progression in symptomatic ALS mice model.

\section{Methods}

\section{Animals}

All mice were handled in accordance with the guidelines of the United States National Institutes of Health (Bethesda, MD). The protocols were approved by the Institutional Animal Care and Use Committees of the Korea Institute of Oriental Medicine. Hemizygous transgenic B6SJL mice carrying a glycine to alanine base pair mutation at the $93^{\text {rd }}$ codon of the cytosolic $\mathrm{Cu} / \mathrm{Zn}$ superoxide dismutase gene (hSOD $1^{\mathrm{G} 93 \mathrm{~A}}$ ) were originally obtained from the Jackson Laboratory (Bar Harbor, $M E)$. Transgenic mice were identified by PCR as described previously [4]. The hSOD ${ }^{\mathrm{G} 93 \mathrm{~A}}$ mice developed the initial signs of neuromuscular deficits, such as leg tremors and loss of the hindpaw extension reflex, at approximately 15 weeks of age. At 16 weeks, they showed marked locomotor impairment with paralysis and muscular atrophy of the hind limbs. These animals died due to respiratory failure at 18-20 weeks of age. The 14-week-old transgenic mice were considered to be symptomatic; mice of this age were used for the study. All mice were kept in standard housing with free access to water and standard rodent chow.

\section{Bee venom treatment}

Bee venom was purchased from Sigma (St. Louis, MO) and diluted with saline. At a dose of $0.1 \mu \mathrm{g} / \mathrm{g}$, bee venom was bilaterally injected (subcutaneously) into 14week-old (98 day old) male hSOD1 ${ }^{\text {G93A }}$ transgenic mice (hSOD1 ${ }^{\text {G93A }}-\mathrm{BV}, \mathrm{n}=11$ ) at the Zusanli (ST36) acupoint, which is known to mediate an anti-inflammatory effects [19]. BV treatment was performed two times a week at a dose of $0.1 \mu \mathrm{g} / \mathrm{g}$. According to the human acupoint landmark and a mouse anatomical reference 
[20], the ST36 point is anatomically located at $5 \mathrm{~mm}$ below and lateral to the anterior tubercle of the tibia. Control animals were bilaterally injected (subcutaneously) with an equal volume of saline at the ST36 acupoint (hSOD1 ${ }^{\mathrm{G} 93 \mathrm{~A}}, \mathrm{n}=11$ ).

\section{Behavioral analysis (rotarod test)}

Mice were trained for 1 week in order for them to acclimate to the apparatus. After training of the hSOD1 ${ }^{\text {G93A }}$ mice, their basal motor activity was measured with a rotarod apparatus (Ugo, Basil, Italy). Motor coordination was assessed by measuring the length of time that the mice remained on the rotating rod $(10 \mathrm{rpm})$ as was previously described [21].

Each animal underwent three trials and the average time spent on the rod was determined for each group. Rotarod testing was conducted at the same time to reduce environmental variables such as light cycle and temperature.

\section{Life span study}

For lifespan analysis, SOD $1{ }^{\mathrm{G} 93 \mathrm{~A}}$ mice were assessed for a total of 100 days and divided into the following treatment groups: saline-treated SOD1 ${ }^{\mathrm{G} 93 \mathrm{~A}}$ mice $(\mathrm{n}=11)$ and SOD1 ${ }^{\text {G93A }}$ mice treated with BV at 14 weeks (98 day old) old $(n=11)$. We defined "death" that is, the end point of life for hSOD1 ${ }^{\text {G93A }}$ mice as the first day on which the mouse stopped movement on either side, after which time the mouse was no longer able to eat due to severe hindlimb paralysis. Mice were then sacrificed to reduce further pain from respiratory failure according to animal care guidelines. The life span analysis was carried out in male SOD $1{ }^{\mathrm{G} 93 \mathrm{~A}}$ mice. Survival statistics were analyzed by Kaplan-Meier survival curves by Prism 4.0 software (GraphPad Software, San Diego, CA) and Sigmaplot 10 software (Systat Software, Inc. Richmond, CA).

Values were analyzed by a one-way ANOVA followed by a Dunn's multiple-comparison test. All statistics were performed and graphs were developed using Prism 4.0.

\section{Tissue processing and immunohistochemistry}

At 18 days after treatment with BV or saline, hSOD1 ${ }^{\text {G93A }}$ mice were deeply anesthetized with pentobarbital. They were transcardially perfused with phosphate-buffered saline (PBS), followed by a perfusion with a fixative solution containing 4\% paraformaldehyde in PBS. The spinal cord and brain were dissected out and fixed overnight in $4 \%$ paraformaldehyde at $4{ }^{\circ} \mathrm{C}$, transferred to $30 \%$ sucrose, and then frozen. The spinal cord and brainstem were embedded in OCT compound and serially cut on a cryostat into $40-\mu \mathrm{m}$ thick coronal sections. The sections were then floated in PBS and quenched with 30\% methanol and hydrogen peroxide to eliminate endogenous peroxidase activity. After blocking in 5\% normal goat serum at room temperature, sections were incubated with the primary antibodies, which included Iba-1 (Wako, Osaka, Japan) at 1:5000 or TNF- $\alpha$ (Cell Signal, Beverly, MA) at 1:100. All tissue sections were rinsed in PBST (PBS with $0.3 \%$ Tween 20 ) and incubated in secondary antibody (1:1000) for $1 \mathrm{~h}$. Following incubation, all sections were rinsed and stained using Vectastain $A B C$ kits (Vector, Burlingame, CA) according to the manufacturer's instructions. For visualization, 3, 3'-diaminobenzidine (DAB) $-\mathrm{H}_{2} \mathrm{O}_{2}$ substrate was used with a hematoxylin counterstain. After rinsing, all samples were dehydrated in increasing concentrations of ethanol, cleared in xylene, and coverslipped using Permount mounting medium (Fisher Scientific, Pittsburgh, PA). Immunostained tissues were observed with a light microscope (Olympus, Tokyo, Japan). Every fifth spinal cord or brainstem section $(50 \mu \mathrm{m})$ from saline- $(\mathrm{n}=3)$ or BV-treated hSOD ${ }^{\mathrm{G} 93 \mathrm{~A}}$ mice $(n=4)$ was stained with Iba 1 or TNF- $\alpha$ antibody. Cell counting for immunoreactive cells was performed using an image analysis software (IMT $i$-solution, Hackettstown, NJ).

\section{Western blot}

At 14 days after treatment with BV or saline, brains and spinal cords were dissected and homogenized in RIPA buffer (50 mM Tris-Cl pH 7.4, 1\% NP-40, 0.1\% SDS, and $150 \mathrm{mM} \mathrm{NaCl}$ ). Homogenized tissues were centrifuged at $14,000 \mathrm{rpm}$ for $20 \mathrm{~min}$ at $4^{\circ} \mathrm{C}$. Proteins were quantified using the BCA assay kit (Pierce, Rockford, IL). Samples were electrophoresed through SDS-polyacrylamide gels and transferred to nitrocellulose membranes. Blots were blocked with $5 \%$ non-fat milk in TBS for $1 \mathrm{~h}$ prior to incubation with antibodies. Various primary antibodies were utilized in this study, including anti-SOD1 (Calbiochem, La Jolla, CA), anti-tubulin (Abcam, Cambridge, UK), anti-Akt (Cell Signaling, Beverly, MA), anti-pAkt (Cell Signaling), anti-p38 (Cell Signaling), anti-phosphop38 (Cell Signaling), anti-Iba 1 (Wako, Osaka, Japan), and anti-active caspase-3 (Calbiochem). Blots were probed with HRP-conjugated antibodies (SantaCruz, Santa Cruz, CA) and developed with enhanced chemiluminescence (ECL) reagents (Amersham Pharmacia, Piscataway, NJ).

\section{Transmission Electron Microscopy (TEM)}

BV-treated hSOD $1^{\mathrm{G} 93 \mathrm{~A}}$ mice and age-matched controls were sacrificed and perfused with $2 \%$ glutaraldehyde. The procedure of sample preparation for TEM was performed as previously described [22].

\section{Statistical analysis}

Results are expressed as means \pm SEM values. Statistical evaluations were conducted using the Mann-Whitney $\mathrm{U}$ test for comparisons between BV-treated and 
age-matched untreated hSOD1 ${ }^{\mathrm{G} 93 \mathrm{~A}}$ mice. A $t$-test was used to compare the immunoblotting and immunohistochemical data between the BV-treated mice and the age-matched untreated hSOD1G93A mice. $\mathrm{P}$ values less than 0.05 were considered significant. All analyses were performed with SPSS 12.0 software (SPSS, Chicago, IL).

\section{Results}

The BV treatment increases survival rate and motor activity in symptomatic $\mathrm{hSOD} 1^{\mathrm{G} 93 \mathrm{~A}}$ transgenic mice To determine the effects of BV on the survival and motor activity of hSOD $1^{\mathrm{G} 93 \mathrm{~A}}$ mice, BV $(0.1 \mu \mathrm{g} / \mathrm{g})$ was bilaterally administered (subcutaneously) at ST36 (Figure 1). As shown in Figure 2, the BV-treated hSOD $1^{\text {G93A }}$ group displayed a 1.3-fold increase in motor function at 7 days after treatment with BV as determined by the rotarod behavioral test compared to agematched control mice. Furthermore, we observed that BV-treated mice had a delay in disease onset and paralysis compared to saline-treated hSOD $1^{\mathrm{G} 93 \mathrm{~A}}$ mice. Next, we examined the survival rate to determine whether BV treatment prolonged the life span of hSOD1 ${ }^{\mathrm{G} 93 \mathrm{~A}}$ mice. The expected life span was assessed by Kaplan-Meier survival analysis. The median survival of the BV-treated group (139 \pm 3.5 days) was $18 \%$ greater than control group (117 \pm 3.1 days). The Kaplan-Meier probability of survival analysis showed that the BV-treated group had a significantly improved survival rate $(160 \pm 3.5$ days $)$ compared to the control group (143 \pm 3.1 days) (Figure $3)$. However, there was no significant difference in body weight before and after BV treatment (data not shown). These results indicate that BV acted therapeutically against the onset of motor dysfunction as well as against disease progression in $\mathrm{hSOD} 1^{\mathrm{G} 93 \mathrm{~A}}$ mice.

\section{BV reduces microglial cell activation and neuroinflammation}

Microglia activation can be observed in virtually all CNS pathologies including ALS. However, the role of the microglial response in many CNS disorders remains ambiguous, given that these cells exhibit both neuroprotective and neurotoxic effects [23]. To demonstrate whether BV affected neuroinflammation in a familial ALS animal model, we studied the relationship between microglia activation and inflammatory factors in symptomatic hSOD $1^{\mathrm{G} 93 \mathrm{~A}}$ mice. For this experiment, BV or saline was injected at ST36 in 14-week-old hSOD ${ }^{\text {G93A }}$ mice. The effect of BV on activated microglial cells monitored using the Iba- 1 antibody in both the brainstem and lumbar spinal cord of symptomatic hSOD $1^{\mathrm{G} 93 \mathrm{~A}}$ mice. As shown in Figure 4A, the expression level of Iba-1 was dramatically reduced in both the brainstem and spinal cord of BV-treated mice in comparison with the control group. Next, we immunostained lumbar spinal cord sections from BV- or saline-treated mice (Figure 4B-G). At a low magnification, Iba-1 immunoreactivity was detected in both the white and gray matter of the spinal cord in hSOD $1^{\text {G93A }}$ transgenic mice (Figure 4B,C). At a higher magnification, Iba-1 immunoreactivity in the ventral horn of BV-treated hSOD $1^{\mathrm{G} 93 \mathrm{~A}}$ mice was significantly reduced ( $\sim 2.8$ times) as compared to the identical area in control mice (Figure 4F). In the brainstem of mutant SOD1 mice, Iba-1 immunoreactive cells were detected as well (Figure 4D,E). BV caused an approximate 2.4 fold decrease in microglial activity within the facial nucleus of the brainstem (Figure 4G).

In order to determine whether BV suppressed neuroinflammation by inhibiting of the release of the proinflammatory cytokine TNF- $\alpha$, we further examined the

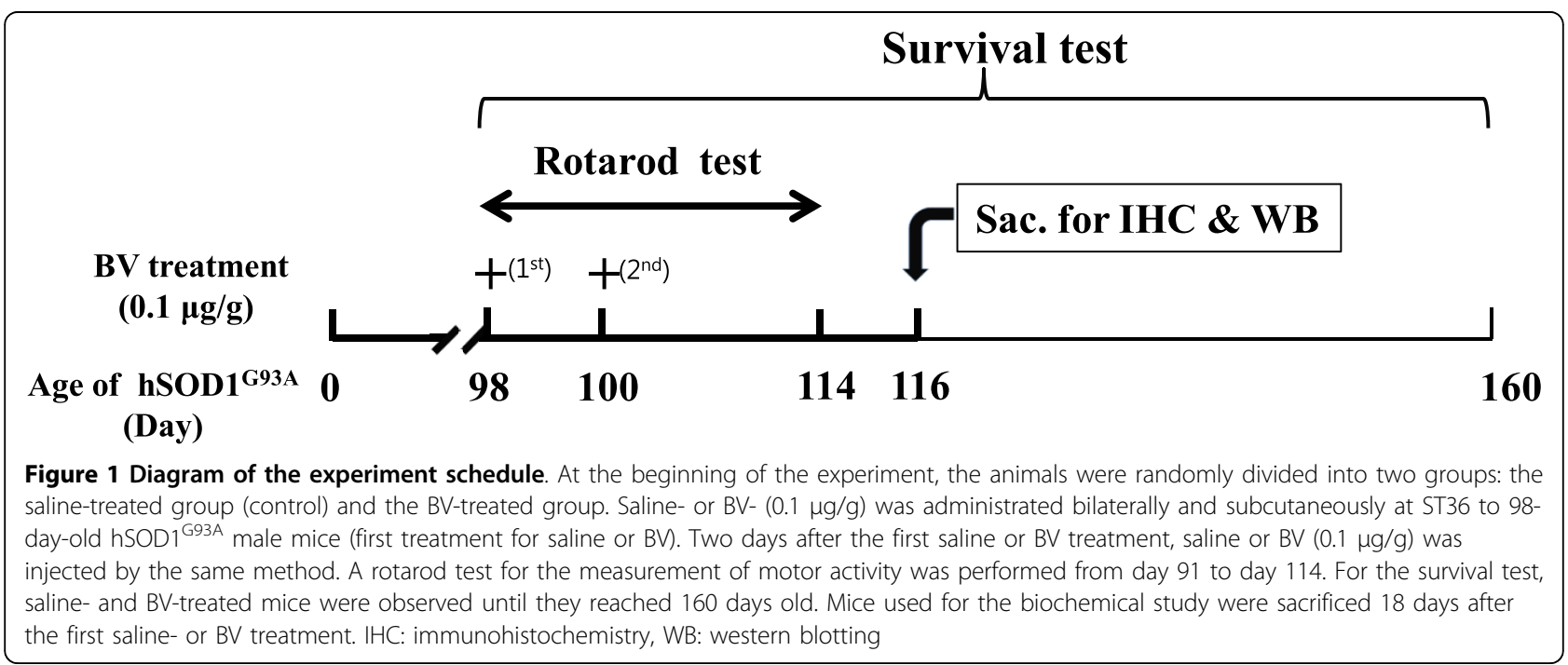




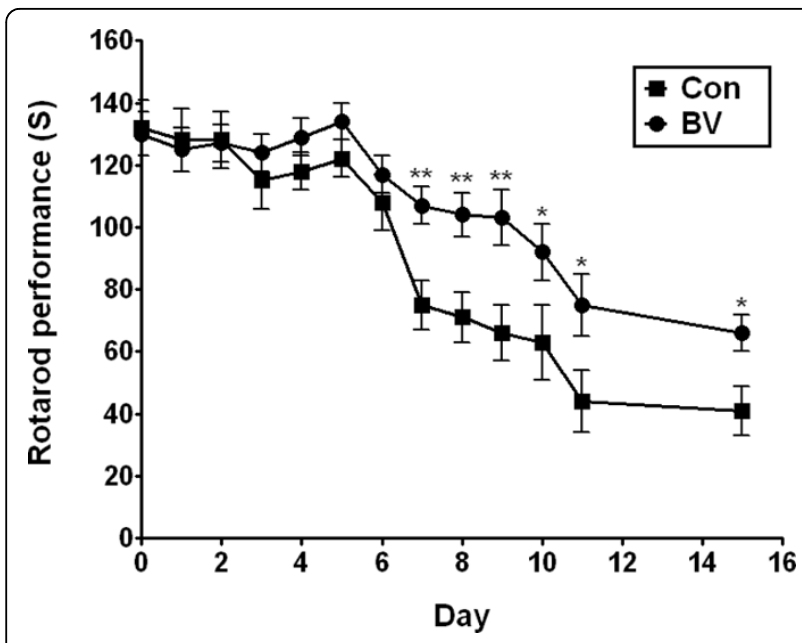

Figure 2 Effects of $B V$ on rotarod performance of hSOD $1{ }^{\text {G93A }}$ mice. BV delays the onset of motor impairment in $\mathrm{hSOD} 1^{\mathrm{G}}{ }^{\mathrm{A} A}$ transgenic mice. B6 G93A-SOD1 mice ( $n=11 /$ group) were injected with saline (squares) or BV at ST36 (circles). Values represent the mean \pm SEM. Significantly improved motor performance was evident at most time points between 7-9 days after BV treatment as compared with controls. The Mann-Whitney $U$ test was used to compare saline-treatment versus BV-treatment in $\mathrm{hSOD} 1^{\mathrm{G}}{ }^{3} \mathrm{~A}$ transgenic mice $\left({ }^{* *} p<0.005,{ }^{*} p<0.05\right)$. S: second, Con: saline treated-mice, BV: bee venom treated-mice.

level of TNF- $\alpha$ by immunohistochemistry in BV- or saline-treated familial ALS mice. As expected, TNF- $\alpha$ immunoreactivity in hSOD $1^{\text {G93A }}$ mice was largely confined to the facial nucleus of the brain stem and motor neurons in the anterior horn of the spinal cord (Figure $5 \mathrm{~A}, \mathrm{C}$, and $5 \mathrm{E}$ ). Interestingly, BV caused a significant 4fold reduction in TNF- $\alpha$ immunoreactivity in both the brainstem and lumbar spinal cord (Figure 5B,D, and 5F$H)$. These results suggest that BV treatment may be involved in an anti-neuroinflammatory responses that reduces motor neuron degeneration and prolongs the life span of hSOD1 ${ }^{\mathrm{G} 93 \mathrm{~A}}$ transgenic mice at the symptomatic stage.

\section{BV inhibits cell death and disruption of mitochondrial structure in $\mathrm{hSOD} 1^{\mathrm{G} 93 \mathrm{~A}}$ mice}

The caspase family plays an important role in the pathogenesis of CNS disorders [24]. Caspase- 3 activation, which has been detected in ALS patients [25], and mutant SOD1 expression have been shown to induce caspase-dependent neuronal apoptosis in vitro [26]. To assess whether BV affected mitochondrial cell death in symptomatic mutant SOD1 mice, we performed immunoblotting analysis of homogenates of the spinal cord and brainstem using a caspase- 3 antibody. Expression levels of the active caspase-3 fragment were markedly increased in the lumbar spinal cord of hSOD $1^{\mathrm{G} 93 \mathrm{~A}}$ mice, but caspase- 3 expression was maintained at a very low

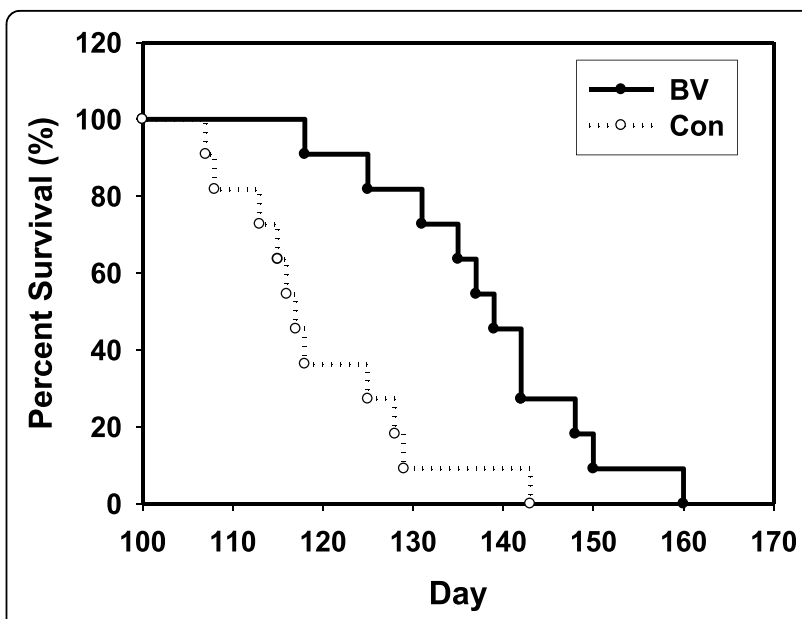

Figure $3 \mathrm{BV}$ prolongs the survival of $\mathrm{hSOD} 1^{\mathrm{G} 93 \mathrm{~A}}$ transgenic mice. A Kaplan-Meyer analysis illustrates the significant benefits from BV $(0.1 \mu \mathrm{g} / \mathrm{g} / 98$ day) compared with the control regarding survival rate. Mice were bilaterally injected with saline (open circles) or BV (closed circles) at ST36 (subcutaneously). The mean, median, minimum, and maximum age of death in saline-treated hSOD $1^{\mathrm{G} 93 \mathrm{~A}}$ mice are 120, 117, 107, 143 day, respectively. The mean, median, minimum, and maximum age of death in BV-treated hSOD1 ${ }^{\mathrm{G} 93 \mathrm{~A}^{\prime}}$ mice are 139, 139, 118, and 160 day, respectively. Con: saline-treated mice, $\mathrm{BV}$ : bee venom-treated mice.

level in the spinal cord of BV-treated hSOD1 ${ }^{\mathrm{G} 93 \mathrm{~A}}$ mice. More specifically, caspase- 3 expression was found to be reduced by $80 \%$ relative to the level observed in untreated hSOD1 ${ }^{\mathrm{G} 93 \mathrm{~A}}$ mice (Figure 6A).

Next, we asked whether BV affected the mitochondrial ultrastructure in the lumbar spinal cord of symptomatic hSOD1 ${ }^{\text {G93A }}$ mice. We used transmission electron microscopy (TEM) to visualize mitochondria from the anterior horn of the lumbar spinal cord from BV- or saline-treated mutant SOD1 ${ }^{\mathrm{G} 93 \mathrm{~A}}$ mice. In symptomatic familial hSOD1 ${ }^{\text {G93A }}$ mice, mitochondria displayed vacuolation and broken cristae (Figure 6B,D). By contrast, mitochondrial cristae were shaped as compact tubules in an orderly fashion in the ventral horn of the spinal cord from BV-treated (Figure 6C,E). These studies demonstrated that BV serves a protective role in regulating mitochondrial structure and cristae morphology.

Next, we asked whether BV-induced signal transduction pathways affected neuron death and gliosis in hSOD1 ${ }^{\text {G93A }}$ mice. As shown in Figure 7A, Western bolt analysis revealed an increase in the expression of the neuronal cell marker MAP2 in both the brainstem and lumbar spinal cord of BV-treated symptomatic hSOD $1^{\text {G93A }}$ mice. In addition, GFAP was significantly reduced in the $\mathrm{BV}$-treated brainstem and spinal cord when compared with age-matched familial mutant SOD1 mice (Figure 7B). These data suggest that BVtreatment at ST36 had a neuroprotective effect via activation of a cell survival signal transduction pathway, 
which reduced ALS-associated motor neuron death from gliosis and neuroinflammation.

\section{The effect of BV on cell survival signal transduction pathways}

To evaluate the mechanism by which BV mediates this neuroprotective activity, we examined the expression levels of phospho-p38 MAPK and several anti-apoptotic markers, such as phospho-Akt and phospho-ERK, in symptomatic hSOD1 ${ }^{\text {G93A }}$ mice. Western blotting experiments using anti-phospho-p38 or Ser435-phospho-specific Akt1 antibodies demonstrated activation of Akt-1 and deactivation of phospho-p38 in the spinal cord and brainstem following treatment with BV (Figure 7D,E). Furthermore, BV-treatment dramatically increased the expression of phospho-ERK in the spinal cord and brainstem of familial mutant SOD1 mice (Figure 7F). These biochemical results support that previous observations indicating that BV at ST36 improved motor activity and increased survival rates of hSOD1 ${ }^{\mathrm{G} 93 \mathrm{~A}}$ mice (Figures 2 and 3).

\section{Discussion}

The molecular targets and signaling pathways influencing paralysis in ALS are not completely understood. To date, several pathogenic mechanisms have been identified that contribute to atrophy and paralysis in ALS patients, including protein misfolding, mitochondrial dysfunction, oxidative damage, cytoskeletal abnormalities, defective axonal transport, glutamate excitotoxicity, inadequate growth factor signaling, and neuroinflammation.

In this study, we demonstrated that administration of $\mathrm{BV}$ at a symptomatic stage of disease progression resulted in increased motor activity and a prolonged life span in comparison with age-matched control mice. Furthermore, we observed that BV prevented neuroinflammationinduced death of motor neurons and alleviated mitochondrial disruption in symptomatic SOD $1^{\text {G93A }}$ transgenic mice.

Microglia in the CNS are immunologically active and capable of responding to events associated with formation of the neuronal-glial environment. Moreover, evidence indicating that microglial cells are involved in the progression of ALS pathogenesis has emerged from several lines of investigation. For example, activated microglia are typically found in ALS patients and in mouse models of ALS [27]. In addition, microglia have been shown to increase pro-inflammatory cytokines, reactive oxygen species (ROS), and glutamate in response to stimuli from neurons and astrocytes, which include proinflammatory cytokines and neurotrophic factors [28].

The pro-inflammatory cytokine TNF- $\alpha$ is a member of the TNF superfamily, which is a class of cytokines known to promote inflammatory signaling [29]. TNF signaling occurs through many factors including intracellular signaling pathways, nuclear factor kappa-B (NF-kB), p38, and c-Jun N-terminal kinase (JNK), which results in a number of responses such as inflammation, proliferation, cell migration, and necrosis [30,31]. TNF signaling has been shown to have several important functions within the CNS [32], including injurymediated microglial and astrocyte activation [33]. Elevated levels of TNF- $\alpha$ and activation of TNF- $\alpha-$ mediated signaling pathways are evident in a large number of neurological disorders including AD, PD, and ALS [13-15]. In addition, cytokines TNF- $\alpha$ has been proposed to be involved in ALS-like microglial activation [16], and inflammation by this cytokine has been shown to induce motor neuron death [17]. In accordance with previous reports $[27,15]$, the present study showed that microglial cell activation and increased TNF- $\alpha$ cytokine levels were involved in ALS pathologies involving both the spinal cord and the facial nucleus of the brainstem in symptomatic familial hSOD $1^{\mathrm{G} 93 \mathrm{~A}}$ mice (Figures 4, 5). Interestingly, we found that BV administration at the ST36 acupoint significantly attenuated neuroinflammatory events triggered by TNF- $\alpha$ and microglial cell activation in motor function relatedstructures within the spinal cord and brainstem (Figures 4A, 5G-H). Some reports have also suggested that BV may be an efficient treatment for multiple sclerosis (MS) and other autoimmune diseases based on the inhibition of TNF- $\alpha$ production $[34,35,18]$. These findings suggest that BV treatment may be useful for combating inflammation in ALS patients.

Previous reports have indicated that a common mechanism of toxicity associated with the mutant form of SOD1 is the sequential activation of caspase-1 and caspase-3 [36]. Since caspase-3 activation leads to microglial cell activation and mitochondrial dysfunction, we examined whether caspase- 3 inactivation was involved in the anti-inflammatory effect of BV. We found that the levels of active caspase- 3 were significantly reduced in the lumbar spinal cord of hSOD ${ }^{\text {G93A }}$ mice following BV treatment (Figure 6A). Furthermore, the administration of BV prevented the disruption of mitochondrial cristae and vacuolization in the ventral horn of hSOD $1^{\text {G93A }}$ mice at the symptomatic stage (Figure 6B-E). This result suggests that BV treatment had an anti-inflammatory effect on the CNS of familial mutant SOD1 mice. Thus, we hypothesized that BV-treatment reduced motor neuron death and mitochondrial dysfunction by preventing neuroinflammation. Supporting this idea, BV treatment significantly increased the expression of a neuronal cell marker and reduced GFAP levels when compared with agematched hSOD1 ${ }^{\text {G93A }}$ transgenic mice (Figure 7A-B). Accordingly, a reduced number of astrocytes and diminished cytokine levels positively influenced neuronal survival and inhibited mitochondrial dysfunction which 

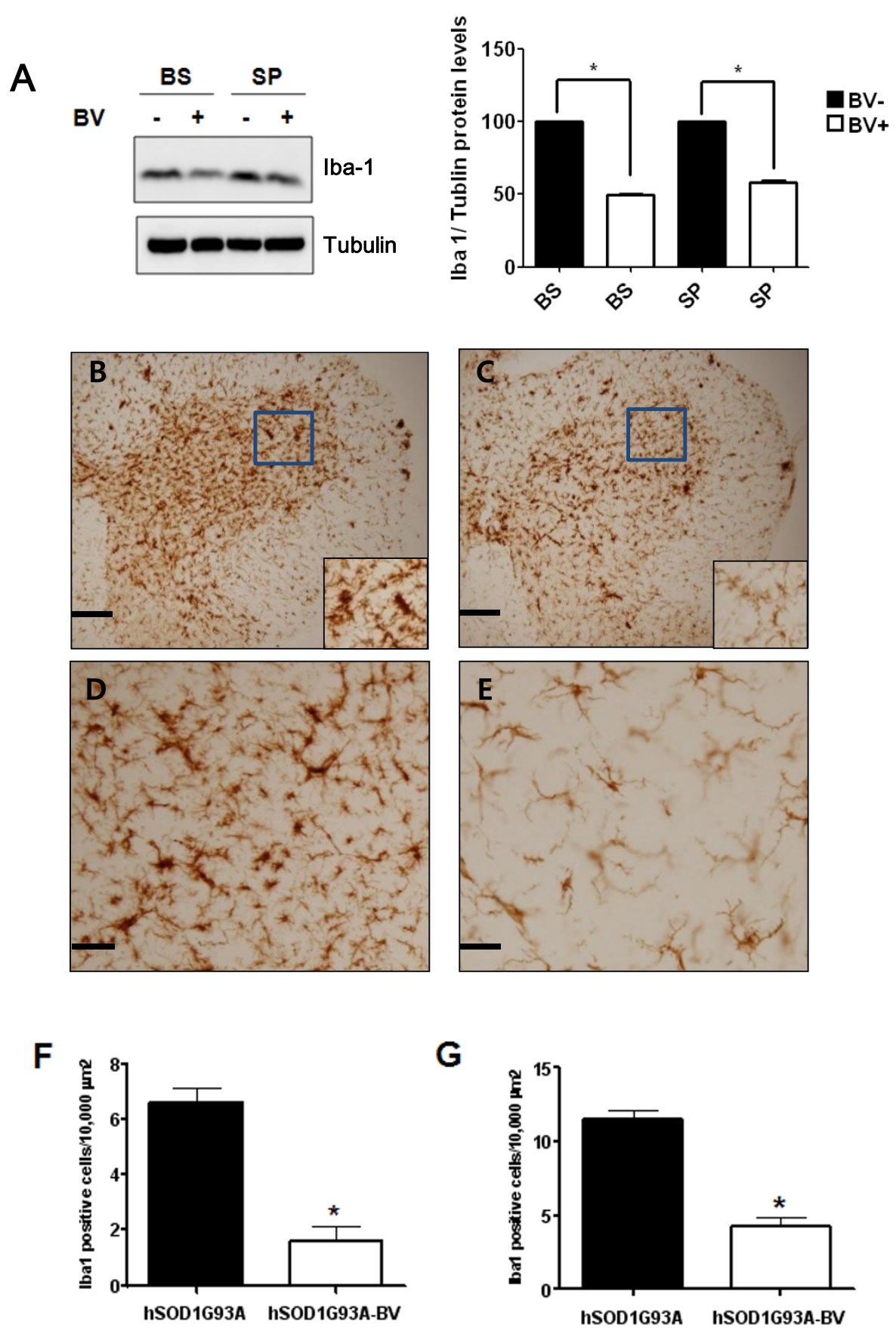

Figure 4 Immunoreactivity (IR) and western blotting for Iba1 in the brainstem and spinal cord. A representative blot of Iba-1 is shown significant reduction of $\mathrm{Iba} I$ in the brainstem and spinal cord of BV-treated $\mathrm{hSOD} 1^{\mathrm{G} 93 \mathrm{~A}}$ mice (A). This experiment was performed using saline- or BV-treated hSOD1 ${ }^{\text {G93A }}$ mice $(n=3)$. Quantitative analysis of immunoblot. The image is representative of three independent experiments. The optical density was measured for each band, and values for lba-1 were compared with tubulin after correcting for the total protein content. The Results of the densitometric quantifications are the means \pm SEM of triplicate samples. The data were analyzed using a $t$-test. ${ }^{*} p<0.01$ versus the corresponding saline-treated group.

Iba1 IR of the lumbar ( $(4)$ spinal cord of $h S O D 1^{G 93 A}$ mice treated with saline (B) or BV (C). Boxes indicate high magnification views of the ventral horn region. Iba1 IR of the facial nucleus of the brainstem from saline- (D) or BV-treated transgenic mice (E). Scale bars $=200 \mu \mathrm{m}(\mathrm{B}, \mathrm{C})$. Scale bars $=100 \mu \mathrm{m}(\mathrm{D}, \mathrm{E})$. Cell counts of Iba1-positive cells in the ventral horn region or brainstem of saline- (black columns, $n=3$ ) or BV-treated mice (white columns, $n=4)(F, G)$. Data are shown as the mean \pm SEM. Data were analyzed with a $t$-test. ${ }^{*} p<0.001$. BV: bee venom, BS: brainstem, SP: spinal cord. 

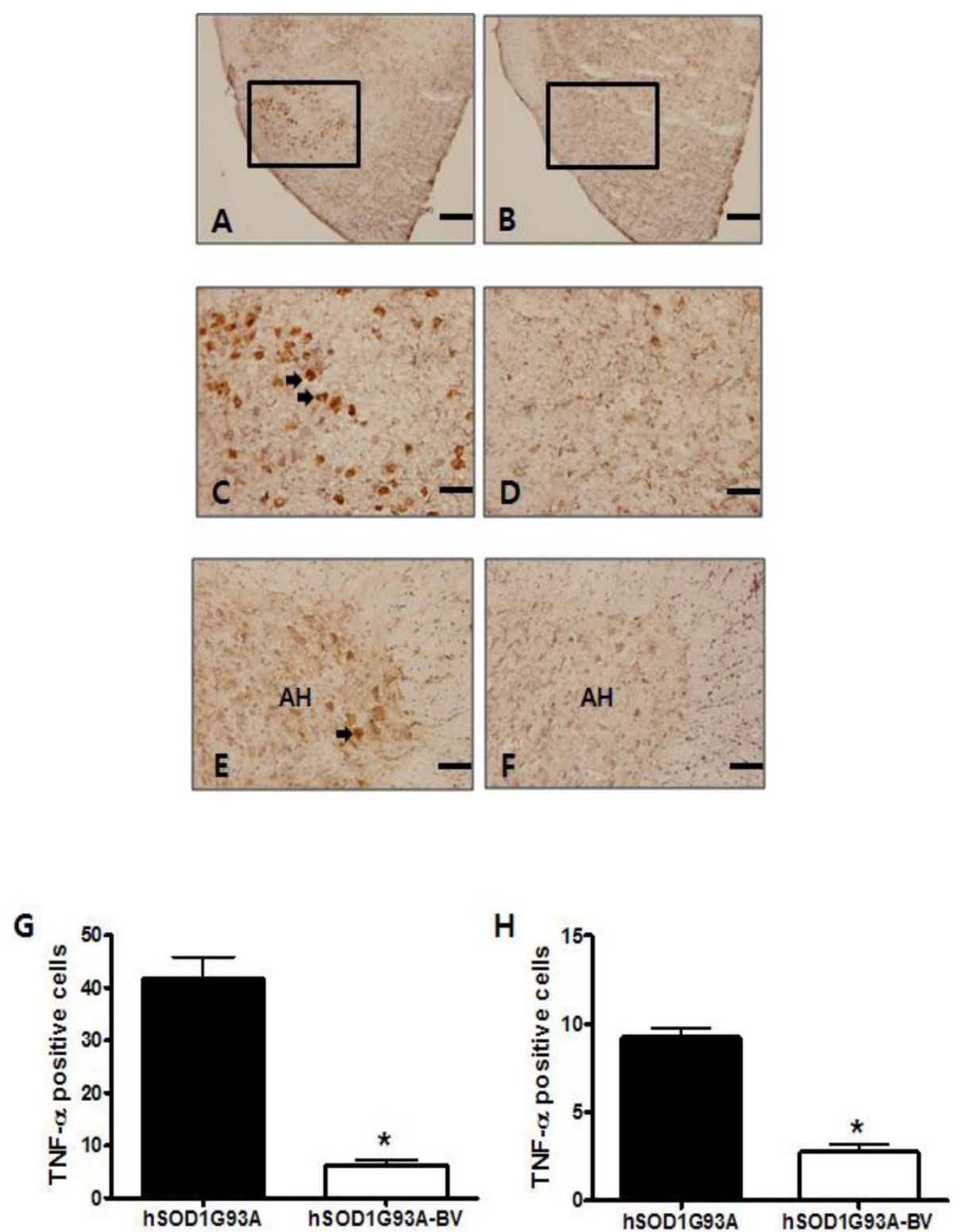

Figure 5 Immunohistochemical study of TNF- $\alpha$ in the brainstem and anterior horns of the lumbar (L4) spinal cord in BV- or salinetreated familial mutant SOD1 mice. TNF- $\alpha$ IR is significantly reduced in the facial nucleus of the brainstem from BV-treated hSOD $1^{\mathrm{G} 93 \mathrm{~A}}$ mice (A, B). Scale bars $=400 \mu \mathrm{m}(\mathrm{A}, \mathrm{B})$. High magnification of boxes (facial nucleus) in A and B (C, D). In the anterior horn of the spinal cord, the number of TNF- $\alpha$-immunoreactive cells was increased in $\mathrm{hSOD1}{ }^{\mathrm{G} 93 \mathrm{~A}}$ mice, but it was reduced by treatment with $\mathrm{BV}(\mathrm{E}, \mathrm{F})$. Scale bars $=100 \mu \mathrm{m}$ (C-F). Cell counting for TNF- $\alpha$ immunoreactive cells in saline- (black columns, $n=3$ ) or BV-treated (white columns, $n=4) h S O D 1^{G 93 A}$ mice $(G, H)$. BV treatment reduced significantly TNF-a immunoreactivity in the brainstem $(G)$ and lumbar spinal cord $(H)$. Data were analyzed with a $t$-test. ${ }^{*} p$ $<0.001$. AH: anterior horn.

otherwise might have led to increased levels of reactive oxygen species (ROS) and glutamate release associated with ALS [37]. With respect to the molecular mechanism underlying $\mathrm{BV}$, we observed that BV treatment triggered a reduction in the activation of $\mathrm{p} 38$ MAPK, which is downstream of the TNF- $\alpha$ signaling pathway in the spinal cord of hSOD1mice (Figure 7D). In contrast, the levels of phospho-AKT and phospho-ERK were increased in both the brainstem and spinal cord of BV-treated hSOD1 mice compared to those of control mice (Figure $7 \mathrm{E}-\mathrm{F})$. These results demonstrate that BV-treatment of familial mutant hSOD1 transgenic mice caused a reduction in pro-inflammatory cytokines and an increase in phospho-Akt and ERK, which may inhibit motor neuronal cell death by preventing neuroninflammation and consequently delay disease onset. 


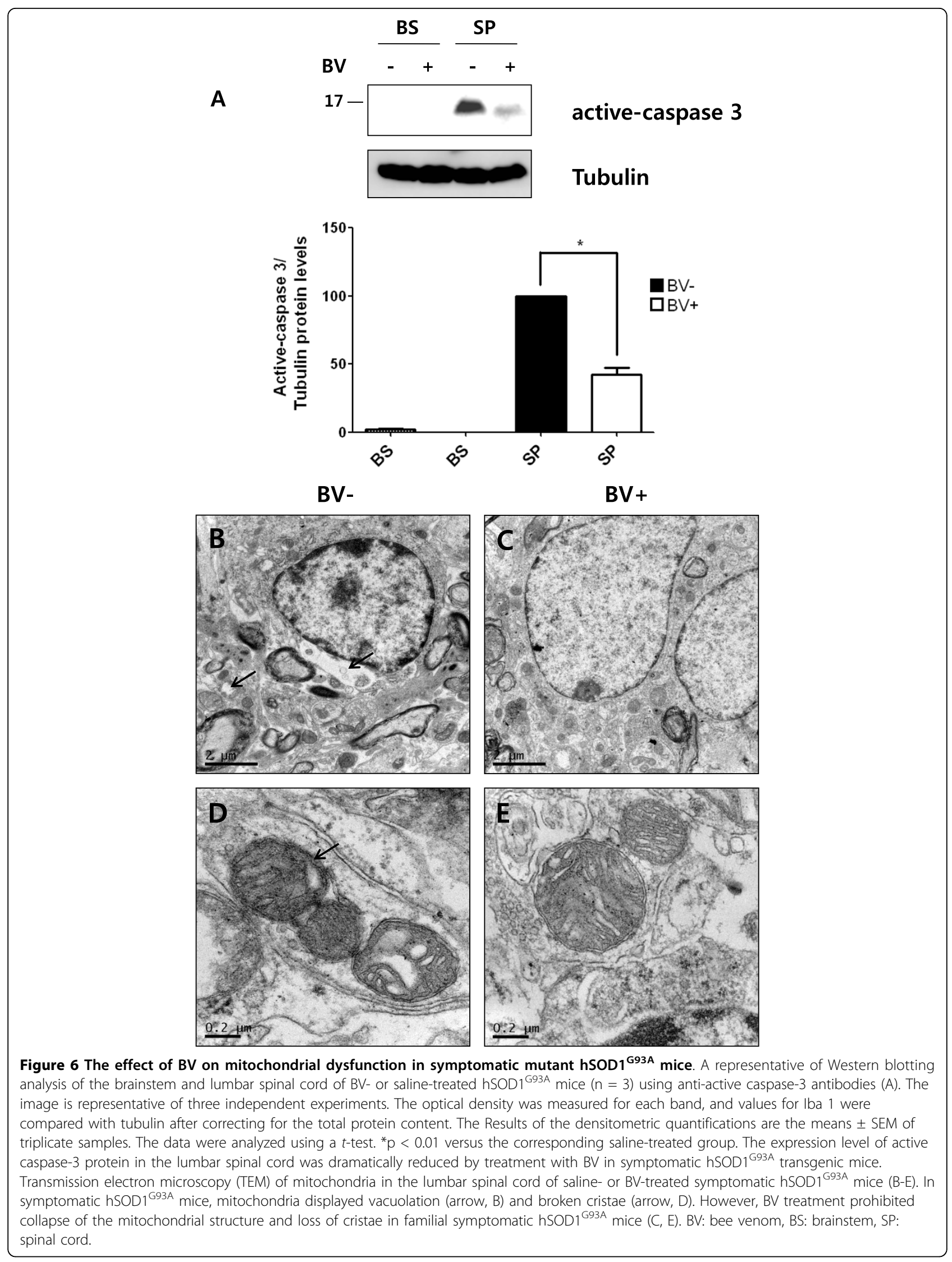





Tub



PAKT

AKT

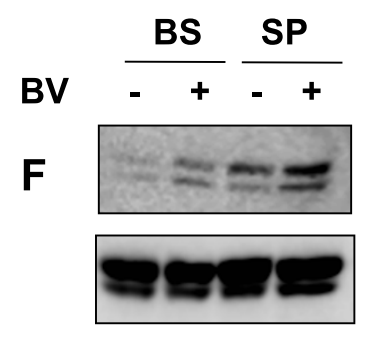

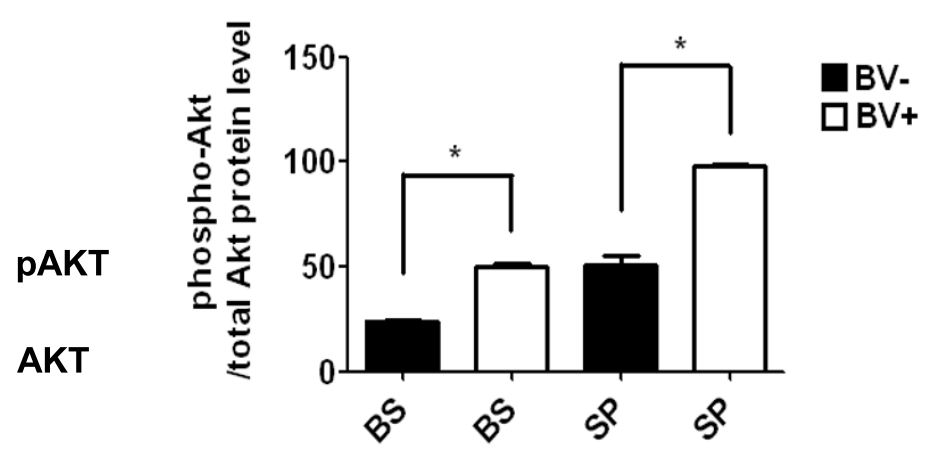
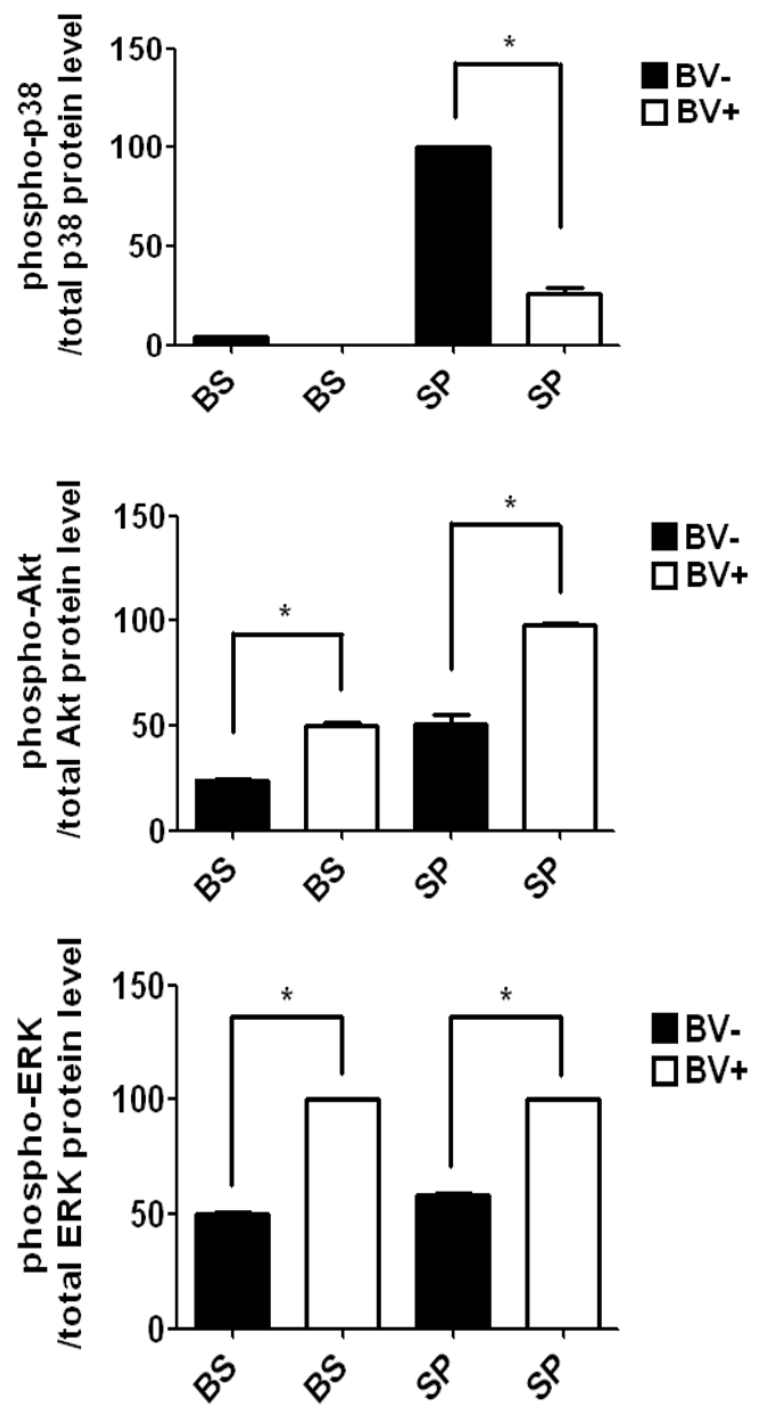

Figure $7 \mathrm{BV}$ treatment reduces the expression of GFAP protein and prevents neuronal cell death via modulation of cell survival signaling pathways. A representative of Western blot analysis shows increased expression of the MAP protein (A), which is reduced in BVtreated $\mathrm{hSOD} 1^{\mathrm{G} 93 \mathrm{~A}}$ mice at the symptomatic stage (B). The intensities of the immunoreactive bands were compared to the corresponding bands from the brainstem or spinal cord of saline-treated mice (A). Quantification of the intensity of the immunoreactive band was compared to the corresponding bands from the brainstem or spinal cord of BV-treated hSOD $1^{G 93 A}$ mice $(n=3)(B) .{ }^{*}$ indicates a non-specific immunoblot band. Western blots show that the expression of active p38 in the spinal cord was reduced by BV treatment compared to the levels observed in agematched hSOD1 ${ }^{\mathrm{G} 93 \mathrm{~A}}$ mice $(n=3)(\mathrm{D})$. The expression level of phospho-Akt protein was increased in the brain stem and lumbar spinal cord by $B V$ treatment (E). The amount of phospho-ERK protein was augmented after BV treatment in tissue extracts from the brainstem and spinal cord of hSDO1 ${ }^{\mathrm{G}}{ }^{\mathrm{A}}$ mice (F). Quantitative analysis of immunoblot. The image is representative of three independent experiments. The optical density was measured for each band, and values for Iba-1 were compared with tubulin after correcting for the total protein content. The Results of the densitometric quantifications are the means \pm SEM of triplicate samples. The data were analyzed using a $t$-test. ${ }^{*} p<0.01$ versus the corresponding saline-treated group. BV: bee venom, BS: brainstem, SP: spinal cord. 


\section{Conclusions}

This study presented that the improved motor activity and prolonged life span of BV-treated hSOD $1{ }^{\mathrm{G} 93 \mathrm{~A}}$ mice were attributable to the neuroprotective effect provide by reduced levels of cytokines, which are typically released by activated microglia and astrocytes. Furthermore, the present study illustrated that BV treatment prevented mitochondrial disruption and served a neuroprotective role in vivo via the activation of cell survival signal transduction pathways, such as the PI3K and ERK pathways, which subsequently protected against the death of motor neurons in symptomatic hSOD $1^{\mathrm{G} 93 \mathrm{~A}}$ mice.

Further challenges remaining will be to determine whether bee venom treatment at other acupoints presents neuro-protective effects against neuroinflammation in symptomatic ALS mice and find the potential bioactive element of bee venom components in vivo and in vitro.

\begin{abstract}
Abbreviations
ALS: Amyotrophic lateral sclerosis; CNS: central nervous system; mtSOD1: mutant SOD1; ST36: Zusanli; fALS: Familial ALS; hSOD1: human Cu-Zn superoxide dismutase 1; TNF- $\alpha$ : tumor necrosis factor-alpha; AD: Alzheimer's disease; IL-1: interleukin-1; NOS: nitric oxide synthetase; MS: multiple sclerosis; PD: Parkinson's disease; IFN- $\gamma$ : interferon-gamma; BV: Bee venom; MAPK: mitogen-activated protein kinase
\end{abstract}

\section{Completing interests}

The authors declare that they have no competing interests.

\section{Acknowledgements}

This research was supported by grants from the Korea Institute of Oriental Medicine (C09020, K09050, C10040).

\section{Author details}

${ }^{1}$ Department of Standard Research, Korea Institute of Oriental Medicine, 483 Expo-ro, Yuseong-gu, Daejeon, 305-811, Korea. ${ }^{2}$ Department of Instrument Development, Korea Basic Science Institute, 113 Gwahag-ro, Yuseong-gu, Daejeon, 305-333, Korea.

\section{Authors' contributions}

EJY designed the experiments and analyzed the data as well as wrote the manuscript. JHJ carried out the rotarod test, immunohistochemistry and performed statistical analyses. SML and HSH participated in the tissue processing of animal for all experiments. SCY contributed technical expertise for TEM. MSL and SMC helped editing of the manuscript. All authors have read and approved the final manuscript. All data collection and observations were completed by a blinded observer.

\section{Received: 19 July 2010 Accepted: 15 October 2010}

Published: 15 October 2010

\section{References}

1. Mulder DW: Clinical limits of amyotrophic lateral sclerosis. Adv Neurol 1982, 36:15-22.

2. Cleveland DW, Rothstein JD: From Charcot to Lou Gehrig: deciphering selective motor neuron death in ALS. Nat Rev Neurosci 2001, 2:806-819.

3. Weishaupt JH, Bartels C, Polking E, Dietrich J, Rohde G, Poeggeler B, Mertens N, Sperling S, Bohn M, Huther G, Schneider A, Bach A, Siren AL, Hardeland R, Bahr M, Nave KA, Ehrenreich H: Reduced oxidative damage in ALS by high-dose enteral melatonin treatment. J Pineal Res 2006, 41:313-323.

4. Rosen DR, Siddique T, Patterson D, Figlewicz DA, Sapp P, Hentati A, Donaldson D, Goto J, O'Regan JP, Deng HX, Rahmani Z, Krizus A, McKennaYasek D, Cayabyab A, Gaston SM, Berger R, Tanzi RE, Halperin JJ,
Herzfeldt B, Bergh RV, Hung W, Bird T, Deng G, Mulder DW, Smyth C, Laing NG, Soriano E, Pericak-Vance MA, Haines J, Rouleau GA, Gusella JS, Horvitz HR, Brown RH Jr: Mutations in $\mathrm{Cu} / \mathrm{Zn}$ superoxide dismutase gene are associated with familial amyotrophic lateral sclerosis. Nature 1993, 362:59-62.

5. Gurney ME, Pu H, Chiu AY, Dal Canto MC, Polchow CY, Alexander DD, Caliendo J, Hentati A, Kwon YW, Deng HX: Motor neuron degeneration in mice that express a human $\mathrm{Cu}, \mathrm{Zn}$ superoxide dismutase mutation. Science 1994, 264:1772-1775.

6. Brown $\mathrm{RH}$, Brown $\mathrm{RH}$, Robberecht W: Amyotrophic lateral sclerosis: pathogenesis. Semin Neurol 2001, 21:131-139.

7. Pasinelli $\mathrm{P}$, Brown $\mathrm{RH}$ : Molecular biology of amyotrophic lateral sclerosis: insights from genetics. Nat Rev Neurosci 2006, 7:710-723.

8. McGeer PL, McGeer EG: Inflammatory processes in amyotrophic lateral sclerosis. Muscle Nerve 2002, 26:459-470.

9. Weydt P, Weydt P, Yuen EC, Ransom BR, Moller T: Increased cytotoxic potential of microglia from ALS-transgenic mice. Glia 2004, 48:179-182.

10. Streit WJ, Mrak RE, Griffin WS: Microglia and neuroinflammation: a pathological perspective. J Neuroinflammation 2004, 1:14.

11. Schindler JF, Monahan JB, Smith WG: p38 pathway kinases as antiinflammatory drug targets. J Dent Res 2007, 86:800-811.

12. Hofman FM, Hinton DR, Johnson K, Merrill JE: Tumor necrosis factor identified in multiple sclerosis brain. J Exp Med 1989, 170:607-612.

13. Fillit $H$, Ding $W H$, Buee $L$, Kalman J, Altstiel L, Lawlor B, Wolf-Klein G: Elevated circulating tumor necrosis factor levels in Alzheimer's disease. Neurosci Lett 1991, 129:318-320.

14. Hirsch EC, Hunot S, Damier P, Faucheux B: Glial cells and inflammation in Parkinson's disease: a role in neurodegeneration? Ann Neurol 1998, 44: S115-S120.

15. Poloni M, Facchetti D, Mai R, Micheli A, Agnoletti L, Francolini G, Mora G, Camana C, Mazzini L, Bachetti T: Circulating levels of tumor necrosis factor-alpha and its soluble receptors are increased in the blood of patients with amyotrophic lateral sclerosis. Neurosci Lett 2000, 287:211-214.

16. Wen W, Sanelli T, Ge W, Strong W, Strong MJ: Activated microglial supernatant induced motor neuron cytotoxicity is associated with upregulation of the TNFR1 receptor. Neurosci Res 2006, 55:87-95.

17. Mir M, Asensio VJ, Tolosa L, Gou-Fabregas M, Soler RM, Llado J, Olmos G: Tumor necrosis factor alpha and interferon gamma cooperatively induce oxidative stress and motoneuron death in rat spinal cord embryonic explants. Neuroscience 2009, 162:959-971.

18. Somerfield SD, Brandwein S: Bee venom and adjuvant arthritis. $J$ Rheumatol 1988, 15:1878.

19. Wilms H, Zecca L, Rosenstiel P, Sievers J, Deuschl G, Lucius R: Inflammation in Parkinson's diseases and other neurodegenerative diseases: cause and therapeutic implications. Curr Pharm Des 2007, 13:1925-1928.

20. Yin CS, Jeong HS, Park HJ, Baik Y, Yoon MH, Choi CB, Koh HG: A proposed transpositional acupoint system in a mouse and rat model. Res Vet Sci 2008, 842:159-165

21. Azzouz M, Ralph GS, Storkebaum E, Walmsley LE, Mitrophanous KA, Kingsman SM, Carmeliet P, Mazarakis ND: VEGF delivery with retrogradely transported lentivector prolongs survival in a mouse ALS model. Nature 2004, 429:413-417.

22. Kirkinezos IG, Bacman SR, Hernandez D, Oca-Cossio J, Arias LJ, PerezPinzon MA, Bradley WG, Moraes CT: Cytochrome $c$ association with the inner mitochondrial membrane is impaired in the CNS of G93A-SOD1 mice. J Neurosci 2005, 25:164-172.

23. Wyss-Coray $T$, Mucke $L$ : Inflammation in neurodegenerative disease-a double-edged sword. Neuron 2002, 35:419-432.

24. Hara H, Friedlander RM, Gagliardini V, Ayata C, Fink K, Huang Z, ShimizuSasamata M, Yuan J, Moskowitz MA: Inhibition of interleukin 1beta converting enzyme family proteases reduces ischemic and excitotoxic neuronal damage. Proc Natl Acad Sci USA 1997, 94:2007-2012.

25. Martin LJ, Price AC, Kaiser A, Shaikh AY, Liu Z: Mechanisms for neuronal degeneration in amyotrophic lateral sclerosis and in models of motor neuron death (Review). Int J Mol Med 2000, 5:3-13.

26. Troy CM, Stefanis L, Prochiantz A, Greene LA, Shelanski ML: The contrasting roles of ICE family proteases and interleukin-1beta in apoptosis induced by trophic factor withdrawal and by copper/zinc superoxide dismutase down-regulation. Proc Natl Acad Sci USA 1996, 93:5635-5640. 
27. Boillee S, Vande Velde C, Cleveland DW: ALS: a disease of motor neurons and their nonneuronal neighbors. Neuron 2006, 52:39-59.

28. Moisse K, Strong MJ: Innate immunity in amyotrophic lateral sclerosis. Biochim Biophys Acta 2006, 1762:1083-1093.

29. Wajant $H$, Pfizenmaier $K$, Scheurich P: Tumor necrosis factor signaling. Cell Death Differ 2003, 10:45-65.

30. Ware CF: Network communications: lymphotoxins, LIGHT, and TNF. Annu Rev Immunol 2005, 23:787-819.

31. Eissner $G$, Kolch $W$, Scheurich P: Ligands working as receptors: reverse signaling by members of the TNF superfamily enhance the plasticity of the immune system. Cytokine Growth Factor Rev 2004, 15:353-366.

32. Tansey MG, Wyss-Coray T: Cytokines in CNS inflammation and disease. In Central Nervous System Diseases and Inflammation. Edited by: Lane TE, Carson M, Bergmann C, Wyss-Coray T. California: Springer; 2008:59-106.

33. Selmaj KW, Farooq M, Norton WT, Raine CS, Brosnan CF: Proliferation of astrocytes in vitro in response to cytokines: A primary role for tumor necrosis factor. J Immunol 1990, 144:129-135.

34. Castro HJ, Mendez-Lnocencio Jl, Omidvar B, Omidvar J, Santilli J, Nielsen HS $J r$, Pavot AP, Richert JR, Bellanti JA: A phase I study of the safety of honeybee venom extract as a possible treatment for patients with progressive forms of multiple sclerosis. Allergy Asthma Proc 2005, 26:470-476.

35. Nam KW, Je KH, Lee JH, Han HJ, Lee HJ, Kang SK, Mar W: Inhibition of COX-2 activity and proinflammatory cytokines (TNF-alpha and IL-1beta) production by water-soluble sub-fractionated parts from bee (Apis mellifera) venom. Arch Pharm Res 2003, 26:383-388.

36. Pasinelli $\mathrm{P}$, Houseweart MK, Brown RH, Cleveland DW: Caspase- 1 and -3 are sequentially activated in motor neuron death in $\mathrm{Cu}, \mathrm{Zn}$ superoxide dismutase-mediated familial amyotrophic lateral sclerosis. Proc Natl Acad Sci USA 2000, 97:13901-13906.

37. Nagai M, Re DB, Nagata T, Chalazonitis A, Jessell TM, Wichterle $H$, Przedborski S: Astrocytes expressing ALS-linked mutated SOD1 release factors selectively toxic to motor neurons. Nat Neurosci 2007, 10:615-622.

doi:10.1186/1742-2094-7-69

Cite this article as: Yang et al:: Bee venom attenuates

neuroinflammatory events and extends survival in amyotrophic lateral sclerosis models. Journal of Neuroinflammation 2010 7:69.

\section{Submit your next manuscript to BioMed Central and take full advantage of:}

- Convenient online submission

- Thorough peer review

- No space constraints or color figure charges

- Immediate publication on acceptance

- Inclusion in PubMed, CAS, Scopus and Google Scholar

- Research which is freely available for redistribution

Submit your manuscript at www.biomedcentral.com/submit 